\title{
Terrorismo: a Contínua Busca por uma Definição
}

\author{
Terrorism: the Continuous Search for a Definition
}

\section{LUCAS PEREIRA REZENDE* NATÁLIA DINIZ SCHWETHER***}

\section{INTRODUÇÃO}

O conceito novo terrorismo foi formulado pela academia na década de 1990, em decorrência, fundamentalmente, dos ataques a bomba no World Trade Center, em Nova Iorque, em 1993, e da utilização do gás sarin no metrô de Tóquio, em 1995. No entanto, apenas após os atentados de 11 de setembro de 2001, nos Estados Unidos, a proposta ganhou visibilidade. Neste momento, grande parte dos jornalistas, tomadores de decisão e estudiosos se convenceram de que havia uma mudança no que se compreendia como terrorismo (Gofas, 2012; Copeland, 2001).

Entretanto, através de uma perspectiva histórica detalhada, observa-se que tanto os agentes estatais quanto os não estatais são recorrentes no emprego do terror como estratégia para conquista e manutenção do poder, aplicando-o de inúmeras formas, dadas suas dinâmica e regularidade próprias (Mannik, 2009). Logo, realizar uma distinção entre o velho e o novo terrorismo é uma operação difícil e deve ser tratada com certo ceticismo (Copeland, 2001). Deve-se buscar, a priori, definir bases sólidas para o termo terrorismo. Diversas foram as tentativas de definição e não há, ainda,

\footnotetext{
* Doutor em Ciência Política (UFRGS). Coordenador da Graduação e professor do Programa de Pós-Graduação em Relações Internacionais da UFSC. E-mail: lucas.rezende@ufsc.br.

** Mestranda do Programa de Pós-Graduação em Relações Internacionais da UFSC. E-mail: natidiniz@gmail.com.
} 
um entendimento comum sobre ela. Neste artigo, procuraremos discorrer sobre algumas dessas tentativas de definição. A complexidade de encontrar um denominador comum que permita realizar uma generalização dos eventos é constantemente frisada. Afinal, o conceito é abstrato em sua essência, o que torna impossível a conjugação de todos os significados, justificativas e interesses particulares em uma única definição (Mannik, 2009). Igualmente, o significado do terrorismo é atribuído por sua vítima e, não raras vezes, "o terrorista para um é o combatente pela liberdade para outro” (Schmid, 1998: 6).

Neste sentido, a análise periodizada de Rapoport (2004) nos será uma ferramenta útil para a compreensão do terrorismo em sua visão macro. Posto que, com vistas a esta evidente imprecisão conceitual, pretende-se instigar uma reflexão a respeito das motivações e consequências da criação de uma nova classificação do terror, mesmo que não se vislumbre a possibilidade de concordância a respeito da definição inicial, dado esta estar envolta por perspectivas políticas, ideológicas e regionais.

Para tanto, partimos do entendimento a priori que muitas das tendências atribuídas como originais e contemporâneas retomam comportamentos já registrados anteriormente. O terrorismo incorrido hoje em dia compartilha características de eventos passados, ele não é um fenômeno qualitativamente novo e está inserido em um contexto histórico cambiante (Crenshaw, 2001; Diniz, 2002).

Portanto, faz-se fundamental que os estudiosos ampliem o seu foco de análise e sejam capazes de observar as distintas ondas que compõe o terror, assim como seu ciclo geracional (Gofas, 2012; Rapoport, 2004). Uma análise focada estritamente nos eventos posteriores à Guerra Fria se torna simplista e deixa de observar variáveis fundamentais, como a política, a social e a econômica (Crenshaw, 2001). Esses, contudo, são aspectos essenciais para compreensão do conceito, pois muitas das ameaças provêm "de fato de um terrorismo político radical, não apenas de um terrorismo religioso" (Sedgiwck, 2004: 796).

Este artigo pretende corroborar a hipótese de que o terrorismo é um fenômeno que evolui através de ondas, nas quais práticas são acrescidas; porém, sua formulação inicial é conservada. Com isso, definições que se enquadram temporalmente não permitem a compreensão total do terrorismo. 


\section{TERRORISMO: MARCOS TEMPORAIS}

Se temos como objetivo compreender mais apropriadamente o conceito de terrorismo é importante realizar um levantamento histórico que permita associá-lo com o desenvolvimento do Estado moderno, caracterizado por um longo processo de acumulação de recursos e apropriação territorial, que teve o uso da violência e a coerção como instrumento.

De acordo com Tilly (1996), os Estados nacionais emergiram na Europa a partir dos esforços dos governantes para adquirir os meios de guerra. A nacionalização foi o processo em que "os Estados criaram exércitos e frotas avultados e recrutados, cada vez mais, entre as próprias populações nacionais, ao mesmo tempo em que os soberanos agregaram as Forças Armadas diretamente à estrutura administrativa do Estado" (idem: $79)$.

No entanto, o Estado moderno é encarregado de proporcionar tanto a segurança física dos cidadãos quanto outros atos de ordenação simbólicos que tornam a vida mais inteligível. Afinal, não é apenas a guerra e seus preparativos que determinam a forma do Estado na contemporaneidade. Este é, igualmente, o resultado de variáveis de concentração de capital, de imposição de coerção e mesmo da posição do Estado no sistema internacional.

O uso legítimo da força pelo Estado moderno foi conquistado a partir da cessão dos poderes de autoridades religiosas, nobres e, também de cada indivíduo, perante o compromisso de uma sociedade mais pacífica. O Estado moderno, mediante a promessa de igualdade e justiça no pós-Revolução Francesa, consolidou uma autoridade capaz de intervir em todos os aspectos da vida dos cidadãos. Entretanto, esse novo poder não foi assimilado beneficamente por todos os indivíduos, uma origem histórica distinta dificultava que se enquadrassem nos padrões estabelecidos e, por isso, se sentiam pressionados com o pacto estabelecido. O terrorismo tornou-se, assim, uma alternativa para desafiar a pretensão do Estado moderno de garantir a ordem para os cidadãos (Zarakol, 2010). $\quad$ N e s s a sucessão de eventos, a Revolução Francesa foi fulcral para ambos os processos de afirmação e contestação da centralidade do poder pelo Estado. Certos ideais liberais, como o pluralismo, o individualismo e a democracia foram firmados. E a palavra terrorismo teve seu primeiro uso registrado, como intimidação governamental durante o Regime do Terror na França revolucionária. Já em 1890, os anarquistas inverteram a lógica do termo, transformando o terrorismo de um ato de Estado para atos praticados con- 
tra o Estado. O terrorismo se tornaria, então, uma ferramenta para a ação política (Nemer; Brant; Lasmar, 2004). Assim, o conceito moderno é mais comumente associado a ações violentas, com intuito de alterar a ordem vigente, realizadas mais por indivíduos e grupos do que por Estados.

Desta forma, em um tempo mais recente, no pós Guerra Fria, observamos que os Estados-nações continuam sendo os principais atores no relacionamento mundial. Seu comportamento permanece moldado pela busca de poder e riqueza, mas o viés cultural conquista grande relevância. Uma vez que a principal motivação do terrorismo é política, evidencia-se que a política externa das potências ocidentais, intervencionistas, gera sentimentos de descontentamento e ódio. De acordo com Huntington (1996: 28), "as distinções mais importantes entre os povos não são ideológicas, políticas ou econômicas. Elas são culturais.”

O fim da Guerra Fria foi singular por encerrar um ciclo de multipolaridade e bipolaridade e dar origem ao novo mundo unipolar (Wohlforth, 1999). Nessa configuração, o único polo impõe sua hegemonia cultural através de valores incontestáveis, a fim de garantir a manutenção de seus interesses. Mediante este cenário o ódio torna-se quase inevitável, na visão de Saint-Pierre (2003: 43):

Quando nenhuma ação diplomática é eficiente para defender interesses postergados, quando nenhum organismo internacional é suficientemente forte para distribuir justiça entre interesses afetados, quando nenhuma forma convencional de violência é eficaz para defendê-los, fica aberta a porta para que o ódio da impotência se manifeste de maneira incontrolável e algumas vezes irracionalmente com relação aos seus objetivos.

Desta forma, logo se desacreditou na possibilidade de uma harmonia com o fim da Guerra Fria, desmistificando o fim da história apregoado por Fukuyama (1989). Houve, de maneira oposta, a multiplicação de conflitos étnicos, a eclosão de novos conflitos entre os Estados (ainda que raros), o ressurgimento de movimentos neocomunistas e neofacistas e a intensificação do fundamentalismo religioso. Nesse contexto, o conceito de segurança começou a adquirir novos contornos, essa redefinição foi importante por possibilitar um estudo que extrapolasse a esfera estatal, atingindo o nível dos indivíduos e grupos sociais, no qual as ameaças são múltiplas.

Segundo Posen (2001/02), a maioria dos países democráticos desenvolvidos estão vulneráveis à ameaça do terrorismo, dada a dificuldade no policiamento das fronteiras, a grande disseminação das armas químicas e biológicas, e, fundamentalmente, devido às discordâncias regionais parti- 
culares em relação à política estatal adotada.

\section{O VELHO X NOVO TERRORISMO}

Segundo Laqueur (1999), o terrorismo pauta-se no emprego sistemático da violência, ou a ameaça de usá-la por parte de entidades menores que o Estado, com a finalidade de instaurar o terror na sociedade para debilitar e/ou destituir o governo, e, assim, produzir uma mudança política. Hoffman (2002: 43) segue a mesma linha argumentativa e evidencia que o terrorismo é a "exploração do medo através da violência ou ameaça de violência, na busca por uma mudança política”, perpetrada por um agente racional: a organização terrorista (Crenshaw, 1981).

Com a aproximação do término da Guerra Fria e o aparente fim do embate ideológico entre as superpotências, ocorreu a eclosão de uma série de conflitos com práticas caracterizadas como pertencentes ao velho terrorismo. Entre elas, observa-se uma motivação ideológica de cunho esquerdista ou étnico-nacionalista e separatista. Nesses casos, a violência era utilizada com intuito de politizar os cidadãos para que se revoltassem contra o sistema imperante, assim como pretendia a independência de outros Estados (Copeland, 2001) 1 .

Observa-se que o terrorismo do imediato pós-Guerra Fria tinha motivações políticas na maioria dos casos, uma vez que suas demandas eram racionalmente negociáveis (Spencer, 2006). Não obstante, para que suas reivindicações fossem consideras legítimas, necessitavam de respaldo da população, e, por isso, o uso indiscriminado da violência era evitado. Segundo Simon e Benjamin (2000: 65), "a violência era orientada e proporcional em seu alcance e intensidade para objetivos políticos práticos”. Nesses casos mais tradicionais de terrorismo, ele pode ser considerado uma prática discriminativa, afinal, realizava uma seleção criteriosa de seus alvos, com o intuito de conquistar a máxima publicidade das ações e apoio do público. Como nos afirma Hoffman (2001: 132, “terrorismo é teatro”. Logo, precisa de atores e audiência para existir.

A fim de conquistarem seus objetivos, os grupos terroristas de então se organizavam de maneira hierárquica, com estruturas de comando e controle rigorosamente definidas e que permitiam o contato entre todas as células (Spencer, 2006; Copeland, 2001). Ademais, as bandas terroristas eram restritas e possuíam poucos membros, os quais recebiam uma profunda capacitação para a prática terrorista, e que eram, na maioria dos casos, 
custeada por um governo nacional (Hoffman, 2001).

Com o início do século XXI, mais especificamente em decorrência dos atentados de 11 de setembro de 2001, ocorre uma alteração no que se compreendia por terrorismo. A dimensão internacional e, consequentemente, seu grande alcance tornam-se fundamentais para o terrorismo do século XXI (Barzegar, 2005). Diferentemente, o velho terrorismo estaria cerceado por limites regionais e se concentraria em determinados espaços regionais, enquanto o novo terrorismo não se restringiria a fronteiras, causando impactos globais. $\mathrm{O}$ novo terrorismo seria, portanto, uma ameaça à ordem, à paz e à segurança internacional, diferentemente do velho terrorismo, que era muito mais percebido como uma ameaça nacional. Com vistas a conquistar esta maior abrangência, o novo terrorismo necessitou criar novas fontes de recursos, como, por exemplo, o tráfico ilegal de drogas e a pirataria, ambos facilitados pela globalização e pelo grande fluxo de pessoas (Raphaeli, 2003).

Como reflexo de sua dimensão internacional, houve uma aparente alteração na forma de organização dos grupos terroristas. Tradicionalmente, eles se estruturavam em células; atualmente, configuram-se como uma rede (Phillips, 1994). Essas redes são, muitas vezes, difusas e amorfas, e não se limitam a práticas convencionais. Novas estratégias são promovidas, como o ciberterrorismo, com o propósito de propagar a sensação de vulnerabilidade no alvo direto (Copeland, 2001).

Observa-se também um crescimento no número de participantes nos grupos terroristas. No entanto, esses novos integrantes são pouco preparados tecnicamente, afinal, não se dedicam exclusivamente ao terror, e se informam, na maioria das vezes, através da internet (Hoffman, 2001). Por outro lado, a letalidade e a ferocidade dos ataques teve um considerável aumento, já que o temor de um contra-ataque é baixo, uma vez que não há um inimigo com endereço certo, ao mesmo tempo em que o nível de tolerância com as estruturas terroristas globais diminuiu (Spencer, 2014; Barzegar, 2005). "Os terroristas de hoje não querem um lugar à mesa, eles querem destruir a mesa e todos sentados nela” (Morgan, 2004: 30).

Desta forma, é recorrente a crença que os novos terroristas possam empregar armas biológicas, químicas, radiológicas e nucleares em seus ataques, a fim de conquistarem uma grande repercussão. Laqueur (1999) argumenta que o novo terrorismo é distinto pois não visa objetivos políticos claros e negociáveis, mas sim a destruição da sociedade e a eliminação de grandes estratos da população. 
Há ainda aqueles que enfatizam outra característica fundamental do novo terrorismo: o papel ascendente da religião, principalmente o islamismo em sua versão radical e fundamentalista, como um dos principais motivadores para os ataques terroristas que ocorrem no pós-Guerra Fria (Laqueur, 1999). Para Gurr e Cole (2000), houve um crescimento alarmante nos últimos anos de organizações terroristas internacionais classificadas como religiosas. Hoffman (2001) aponta que a religião é, de fato, a principal particularidade deste terrorismo moderno, uma vez que produz "sistemas de valores, mecanismos de legitimação, conceitos de moralidade e visão de mundo radicalmente diferentes" (idem: 87). Nessa visão, portanto, para esses seguidores religiosos extremistas a confiança absoluta em uma crença e em seus princípios morais oferece justificativa suficiente para eliminar aqueles que tenham um modo de vida distinto de tais preceitos (Montes, 2003).

Mas nem todos autores vão concordar que existe algo classificável como novo terrorismo. Diniz (2002), por exemplo, avalia criteriosamente autores e/ou instituições que buscaram definir o fenômeno terrorismo. Para o autor, o terrorismo deve ser avaliado como um fenômeno social, e não jurídico - o que tira grande parte das tentativas de definição que passavam pela percepção de ilegalidade. Para melhor definir o terrorismo, é preciso ainda avaliá-lo tanto por seus fins quanto por seus meios. Segundo o autor (idem: 5), “[a] consideração dos meios nos ajudará a distinguir a ação terrorista de outras ações cujas finalidades sejam de mesma natureza; e a consideração dos fins nos ajudará a distinguir a ação terrorista de outras ações que empreguem os mesmos meios."

Nesse sentido, Diniz (idem) afirma que o fenômeno tem características atemporais. $\mathrm{O}$ apelo ao psicológico, em especial via uso do terror, o torna, por exemplo, indiferente à relação numérica das forças combatentes ou à destruição material causada: o objetivo primordial é causar o terror nos alvos diretos e/ou indiretos. Essa característica, por exemplo, o difere da guerrilha, que tem alvos específicos e a destruição material é relevante, senão fundamental. Tampouco pode-se reduzir o terrorismo a um fim político via uso do terror, uma vez que pode haver usos políticos do terror que não são terrorismo ${ }^{2}$. Segundo o autor (idem: 17), no terrorismo,

o objetivo do emprego do terror é permitir romper uma barreira que impede a reunião de forças para mudar uma situação; não há, no caso do terrorismo, uma vinculação direta entre o emprego do terror e o objetivo último buscado pelo grupo, até porque este não dispõe de força suficiente para fazê-lo; seu objetivo é aumentar a sua força. 
Quando se quer obrigar alguém a fazer algo, é preciso dizer a ele o que se quer (...); nos [atos terroristas] (...), a melhor maneira de um grupo não obter o resultado imediato desejado é anunciá-lo.

Em sua definição de terrorismo, portanto, Diniz (2002) o entende como tendo um fim político, mas não ligado diretamente a ele, e sim de forma indireta, como uma parte em uma sequência de ações que têm por fim, aí sim, um objetivo político. O terrorismo pode ser praticado por qualquer ator, estatal ou não-estatal, e tem como meio o uso do terror não com o objetivo imediato de dissuadir ou de compelir, mas de induzir no inimigo um comportamento para alterar uma correlação de forças que lhes é desfavorável.

A definição trazida por Diniz (idem) nos permite entender o terrorismo como um estratagema atemporal, não sendo, portanto, novo. Muito do que se convencionou chamar de novo terrorismo é, na verdade, mudanças na forma de emprego do terror. A dificuldade dessa última definição é compreender - e, logo, achar soluções - para os chamados lobos solitários, aqueles que perpetuam atos terroristas por uma ligação ideológica, sem estarem diretamente ligados às células originais dos grupos terroristas e sem a ciência de seu objetivo político fundamental ${ }^{3}$.

Diante da breve explanação feita, é notório que o novo terrorismo se acerca de muitos temas e ideias já relatados no passado, não sendo, portanto, essencialmente novo. A transformação do velho para o novo terrorismo não é uniforme ou tampouco universal. Quando ocorrem, as mudanças no emprego do terror ocorrem de forma gradual. Portanto, há grupos que adotam aspectos do novo terrorismo enquanto outros mantêm as práticas tradicionais (Neumann, 2009).

A partir de um enfoque histórico, sabe-se que ideologias revolucionárias nunca foram restritas por barreiras fronteiriças. Da mesma forma, a estrutura em rede observada no novo terrorismo não é um fenômeno contemporâneo, foi verificada durante o movimento anarquista uma estratégia semelhante de ação, através de células independentes compostas por radicais violentos (Hoffman, 2001). Igualmente, nota-se que, em oposição ao pensamento comumente aplicado, no qual o novo terrorismo teria se globalizado, de acordo com Goldman (2010), contabilizando-se os casos ocorridos entre os anos 1968 e 2007, na última década, houve um declínio dessa globalização e uma tendência maior à regionalização.

$\mathrm{Na}$ década de 1990 e, mais ainda, na década de 2000, ataques terroristas tornaram-se desglobalizados, o número e percentual de organizações terroristas cometendo ataques fora de suas regiões residen- 
ciais diminuíram [...] na primeira década (1968- 1977) (...), cerca de $17 \%$ das organizações terroristas realizaram ataques fora de suas regiões de base; esses números foram de 13\% na terceira década (1988-1997). Os valores correspondentes foram de $24 \%$ para a segunda década (19781987), mas inferiores a 5\% na última (1998-2007) (Goldman, 2010: 50).

Ademais, a pretensão de conquistar visibilidade com um ato terrorista não foi alterada ao longo dos anos. Para garantir uma repercussão em larga escala e, dessa forma, maximizar o terror, os ataques devem ser de grande dramaticidade; portanto, o número crescente de fatalidades é reflexo de um processo em evolução, não necessariamente representando o novo terrorismo (Spencer, 2014). Afinal, "a letalidade varia significativamente ao longo do tempo e não através da divisão velho x novo” (Gofas, 2012: 27). Se, hoje, novas mídias auxiliam na maior propagação dos atos terroristas, isso não significa que a intenção já não fosse parte do fenômeno original, ainda que em menor escala.

Acrescenta-se a isto a controversa questão do uso de armas de destruição em massa (ADM) pelos supostamente novos terroristas. ${ }^{4}$ Verifica-se, no entanto, que as ADM estão disponíveis há mais de um século, em inúmeros manuais, conselhos para fabricação de bombas e táticas de emprego do terror $^{5}$ (Copeland, 2001). Neste mesmo sentido, ocorre, frequentemente, a vinculação entre o novo terrorismo e ataques suicidas. $\mathrm{O}$ fanatismo de fundamentalistas islâmicos é vinculado a uma maior periculosidade e uma novidade radical. Porém, homens-bomba dispostos a morrer por uma ideologia encontram-se em todas as épocas e tradições culturais, não sendo uma novidade apenas do terrorismo contemporâneo. Dos kamikazes japoneses aos alemães do movimento guerrilheiro Fração do Exército Vermelho, passando pelos Tigres de Liberação do Tâmil, o século XX viu não poucos usos suicidas para emprego do terror (Shweitzero; Montes, 2003).

Recorrentemente, o novo terrorismo é distinguido do velho pela sua motivação religiosa, que, supostamente, estaria em processo de ascensão. Porém, embora Hoffman (2001) seja um autor que sustenta o conceito de novo terrorismo, ele mesmo afirma que, desde os primeiros fanáticos, conhecidos como Zealots ${ }^{6}$, a religião era utilizada como justificativa para a violência terrorista (Hoffman, 2001). Perante isto, é discutível se o imperativo religioso seria capaz de legitimar o conceito de novo terrorismo. No entendimento de Spencer (2006), a motivação religiosa não é uma característica nova, pois faz parte de um processo cíclico que retoma motivações anterio- 
res. De acordo com Rapoport (1984), o terrorismo religioso que assassina aqueles que não professam a mesma religião existe há milhares de anos, e que apenas no século XIX que houve a emergência de motivações políticas (Rapoport, 1984). Esse último ponto não é compartilhado por Diniz (2002), uma vez que o autor identifica o terrorismo como um estratagema, parte de uma mobilização política maior.

De acordo com os autores que sustentam o novo terrorismo, a Al-Qaeda seria um dos poucos exemplos de um grupo que opera nesse molde. Porém, sabe-se que, antes da guerra no Afeganistão, iniciada em 2001, o grupo possuía uma estrutura hierarquizada, agia mediante autorizações de líderes centrais, com pouca autonomia local. Explora-se a possibilidade de sua posterior descentralização ser uma reação à invasão e uma consequente adaptação ao novo cenário, não propriamente uma escolha racional (Crenshaw, 2001). Desta maneira, é fundamental ponderar se, de fato, o que mudou foi o terrorismo ou o mundo em que ele está inserido, uma vez que supõe-se lógico que os terroristas desejem acompanhar essas alterações e compartilhar dos avanços globais (Spencer, 2014).

\section{UMA INTERPRETAÇÃO ALTERNATIVA: O MOVIMENTO ONDULATÓRIO DO TERRORISMO}

Mediante a concepção que uma distinção rígida entre passado e presente não representa a atividade terrorista, pois, na prática, há um encadeamento de comportamentos e uma continuidade das ações, Rapoport (2004) propôs analisar o terrorismo através de uma sequência de ondas. Para o autor, uma onda é um ciclo de atividades em um determinado período, caracterizado por fases de expansão e contenção. Sua característica fundamental, porém não exclusiva, é aquela que atribui nome à onda, pois revela a ocorrência de atividades semelhantes em diferentes países devido a uma mesma energia impulsionadora. Uma vez esgotada, a onda desaparece; em geral, após uma geração.

A primeira onda recente identificada pelo autor, a Onda Anarquista, detinha claros objetivos políticos e, para alcançá-los, utilizava o terror como estratégia. O ponto alto deste período ocorreu na década de 1890, quando foram realizados inúmeros assassinatos de monarcas, primeiros-ministros e presidentes por além fronteiras, demonstrando o caráter internacional desse uso do terror, mesmo que motivado pela política interna dos países (idem). 
A segunda onda, a Onda Anticolonial, foi suscitada com a assinatura do Tratado de Paz de Versalhes ao final da Primeira Guerra Mundial, que teve os ideais reforçados com o término da Segunda Guerra Mundial. Em ambos momentos, os vitoriosos pressionaram os impérios derrotados ao colapso. Diante desse cenário, grupos separatistas, motivados pelo princípio da autodeterminação dos povos, foram os grandes responsáveis pelos atentados terroristas do período (idem).

No entanto, com o término da segunda onda, concomitantemente ao processo de descolonização, não houve significativas alterações no modelo de Estado em vigor. Os nacionalistas revolucionários fizeram seus Estados à imagem de suas metrópoles. Portanto, não se verificou, neste período, uma ideologia que ameaçasse o sistema. Aqueles que não conquistaram a independência mantiveram o emprego das táticas terroristas; porém, em declínio com o passar dos anos (Zarakol, 2010).

Na terceira onda, a Nova Onda Esquerdista, datada da década de 1970, denota-se o desenvolvimento do antiocidentalismo esquerdista nos países em desenvolvimento, manifestado por uma crescente desilusão com a promessa do Estado de Westphalia. Isso motivou lutas localizadas contra determinados Estados, em prol de igualdade, soberania e autonomia (idem).

Conhecida como a nova esquerda, nela verificou-se, de forma análoga à primeira, um misto entre radicalismo e nacionalismo. Em ambas ondas buscava-se obter grande repercussão via maximização dos alvos, o que culminou na retomada do termo terrorismo internacional, em oposição à segunda onda, na qual os alvos militares ganharam destaque. Ademais, no que diz respeito aos assassinatos, na primeira onda eles ocorriam de acordo com seus postos públicos, na onda esquerdista, eram resultado de punições. Já o financiamento estatal, abandonado durante a segunda onda, retornou à prática na terceira onda; os Estados desejavam manter controle sobre o terrorismo (Rapoport, 2004).

Com a perda de fôlego da sua predecessora, emerge no cenário a quarta onda, a Religiosa. Nessa onda, a característica religiosa torna-se o principal diferencial, onde a religião se sobrepõe às identidades étnicas como forma de organização doméstica dos Estados. O fundamentalismo islâmico estaria no centro dessa onda, como grande condutor de ataques no meio internacional, capaz de influenciar demais grupos terroristas em várias regiões do mundo.

A grande inovação tática ficou a cargo da estratégia de terrorismo suicida ${ }^{7}$. Este se caracteriza como uma tática coercitiva, que busca obrigar 
o governo alvo a mudar sua conduta política, através da coação às democracias liberais. Os resultados vêm se demonstrando bastante efetivos, o que faz com que haja um incremento dessa prática nos últimos anos (Pape, 2003).

Como avaliação das causas, de acordo com Rapoport (2004), temos que o fracasso de políticas a favor de uma reforma democrática inspirou a primeira onda. Já na segunda, o tema principal foi a luta pela autodeterminação nacional. Novamente, na terceira onda, observamos clamores pela democracia, pois acreditava-se que os sistemas existentes não eram verdadeiramente democráticos. Por fim, na quarta onda, propõe-se uma conduta pautada no secularismo religioso, o qual, muitas vezes, entra em embate com os ideais democráticos.

Nessa interpretação, compreender as causas da primeira onda é fundamental para a análise das circunstâncias atuais do terrorismo. Nessas duas ondas, a globalização e o terrorismo estiveram correlacionados, da mesma forma que o Estado com maior magnitude internacional estava em relativo declínio econômico, possibilitando a emergência de grupos terroristas em zonas semi-imperiais (Bergezen; Lizardo, 2004). Preconiza-se, assim, em ambas ondas, uma clara tensão entre nações afortunadas e as menos abastadas (Cronin, 2002).

\section{CONCLUSÃO}

Buscamos, nesse trabalho, fazer uma avaliação de algumas das tentativas de definição do terrorismo. Em especial, buscamos compreender e desconstruir o chamado novo terrorismo. Pudemos observar que o terrorismo justificado através do fanatismo religioso não é uma novidade do terrorismo pós-Guerra Fria. Vimos que são poucos os grupos que, na contemporaneidade, possuem a religião como sua única motivação; a maior parte deles tem diferentes interesses, fundamentalmente políticos. Essa constatação corrobora a visão de Diniz (2002) do terrorismo como um fenômeno atemporal, visto como um estratagema parte de uma estratégia maior direcionada por um fim político, cuja característica de emprego da força é o uso do terror e que busca uma alteração na correlação de forças. Não obstante, o emprego da violência de maneira indiscriminada, ou o uso apocalíptico do terror, pode ser compreendido como decorrência de uma tendência já existente, acrescida do desenvolvimento global e de oportunidades e estímulos estruturais circunstanciais. 
Portanto, corroboramos nosso suposto que não há um novo terrorismo, mas, sim, uma evolução tática, ou, nos termos de Rapoport (2004), uma variação cíclica de diferentes tipos de emprego do terror no terrorismo. Laqueur (1999: 80) argumenta que "não há um terrorismo per se, apenas diferentes terrorismos", coexistindo o velho e o novo. O mesmo autor afirma ainda que fixar o estudo em um aspecto específico do emprego do terror necessariamente gera conclusões errôneas, o quadro deve ser analisado por completo.

Desta forma, rejeitar o conhecimento acumulado até então sobre o fenômeno do terrorismo, considerando-o obsoleto, seria um despropósito conceitual, pois que a noção de uma transformação radical da atividade terrorista reforçaria um debate presentificado, sem o aporte histórico fundamental para compreensão do tema. Assim, afirmar que o novo terrorismo começou em 11 de setembro de 2001, restringindo todo o conceito para apenas um evento, demonstra-se uma escolha analítica limitada. O mesmo problema é observado ao se concentrar toda a atenção sobre o terrorismo islâmico, pois o fenômeno terrorismo já existia antes da aparição da Al-Qaeda ou do Estado Islâmico, e, como um estratagema dos fracos, permanecerá existindo mesmo depois que esses grupos sejam extintos.

Igualmente, convém ressaltar a conexão existente entre muitas das características frequentemente elencadas para definir o novo terrorismo e as medidas do contraterrorismo adotadas para combatê-lo. Esta conjunção de acontecimentos, possivelmente, seria a real justificativa para a alteração no modo de se compreender o terrorismo. A figura de um novo inimigo a ser combatido foi essencial para o movimento de securitização recente do terrorismo feito para alterar a política vigente. Em especial na movimentação da Guerra ao Terror, tratava-se de delimitar uma fronteira clara entre aqueles que poderiam ser considerados amigos ou inimigos, reforçando constantemente a imagem do inimigo terrorista como seres irracionais, agressivos e cruéis.

Tratar o terrorismo contemporâneo como novo é reforçar um processo de securitização que, como manobra política, justifica medidas excepcionais de combate. Isso se dá pela retórica que o terrorismo, fundamentalmente o religioso, representa uma ameaça a toda estrutura de poder e valores concebida até então. Ainda que suas táticas tenham evoluído, da mesma forma como as táticas de emprego de forças regulares evolui, o fenômeno terrorismo permanece, em sua lógica estratégica, fundamentalmente o mesmo.

A falta de consenso sobre sua definição por certo perdurará. Afinal de 
RBED, v. 2, no 1 , jan./jun. 2015

contas, o uso normativo do termo terrorismo continua carregado de simbolismo, sendo empregado, de forma geral, como meio de desqualificação e/ou deslegitimação do inimigo. Nosso artigo demonstra que discorrer sobre diferentes definições sobre o terrorismo segue sendo central para o entendimento do tema e, portanto, para a orientação de políticas públicas que, de fato, possam tratar de forma não-ideologizada o fenômeno. 


\section{NOTAS}

1. Exemplo desta definição é o terrorismo perpetrado pelo grupo separatista ETA, que almejava a independência do País Basco, situado em território espanhol e francês.

2. Diniz (2002) pega o caso dos chamados ataques douhetianos (bombardeios nas principais cidades) dos aliados contra o Japão e a Alemanha na II Guerra Mundial. Foi empregado o terror com um fim politico, mas não era terrorista, pois tinha a clara intenção de modificação direta de um comportamento: impelir esses Estados a não mais continuar lutando.

3. Esse é o caso, por exemplo, dos irmãos Tsarnaev, responsáveis pelos atentados na maratona de Boston (EUA), em 2013. Eles não se auto-identificaram como pertencentes a nenhum grupo terrorista, e agiram motivados pela insatisfação com as guerras no Iraque e no Afeganistão. Esse é o caso, por exemplo, dos irmãos Tsarnaev, responsáveis pelos atentados na maratona de Boston (EUA), em 2013. Eles não se auto-identificaram como pertencentes a nenhum grupo terrorista, $\mathrm{e}$ agiram motivados pela insatisfação com as guerras no Iraque e no Afeganistão. 4. A associação é realizada em decorrência do ataque com gás sarin ao metrô de Tóquio, em 1995. Contudo, é possível encontrar relatos de planos para o uso de ADM já em décadas anteriores (Spencer, 2006). É importante notar que Diniz (2002) é um dos autores que não considera esse ataque um atentado terrorista, mas o uso apocalíptico do terror. A intenção, nesse caso, é a destruição pura e simples, não há a intenção de alterar um balanço de forças desfavorável. 5. Vale ainda lembrar que o emprego do terror pode ser ou não terrorista (Diniz, 2002).

6. O Zealots é um movimento originário no século I, que agia violentamente em oposição ao domínio romano, "as forças da história parecem conduzir o terrorismo internacional de volta a um tempo antigo, com ecos do comportamento de terroristas sagrados como Zealots" (Cronin, 2002/03: 38).

7. Tática semelhante à praticada pelos lançadores de bomba anarquistas (Rapoport, 2004). 
RBED, v. 2, no 1 , jan./jun. 2015

\section{TERRORISMO: A CONTÍNUA BUSCA POR UMA DEFINIÇÃO}

\section{RESUMO}

Após os atentados terroristas de 11 de setembro de 2001, um processo de securitização, que incluiu acadêmicos e formadores de opinião, colocou o que ficou cunhado como novo terrorismo como a principal ameaça à paz e segurança internacional. Esse fenômeno seria distinto do velho terrorismo, configurando-se como uma ameaça nova, típica do século XXI. Entretanto, com um olhar mais atento, nota-se que este não seria um fenômeno novo com características próprias da contemporaneidade, uma vez que o que mudou foi a tática do emprego do terror, mas não sua essência fundamental. Apresentamos nesse artigo diferentes interpretações sobre o terrorismo e a dificuldade de se alcançar uma definição única, assumindo que houve mudanças; porém, ressaltando a importância que as mesmas sejam claramente delimitadas, a fim de questionar a validade do emprego do termo novo terrorismo.

Palavras-chave: Segurança Internacional; Velho Terrorismo; Novo Terrorismo; Defesa Nacional.

\section{ABSTRACT}

After the terrorist attacks of September 11, 2001 a securitization process, which included scholars and opinion leaders, put what was coined as new terrorism as the main threat to international peace and security. This phenomenon was supposed to be distinct from the old terrorism, configuring itself as a new threat typical of the 21 st century. However, with a closer look, we note that 21 st terrorism isn't a new phenomenon with special characteristics of its own, since what has changed is the tactics of the use of terror, but not terrorism's fundamental essence. We present in this article different interpretations of terrorism and the difficulty of reaching a single definition. We assume there were changes; however, stressing the importance of clearly defining these changes in order to question the validity of the employment of the tern new terrorism.

Keywords: International security; Old Terrorism; New Terrorism; National Defence. 


\section{REFERÊNCIAS}

Barzegar, Kayhan. (2005) “The Middle East and the 'New Terrorism”. Journal on Science and World Affairs, vol. 1, n. 2, pp:113-121.

Bergesen, Albert; Lizardo, Omar. (2004) "International Terrorism and the World-System." Sociological Theory, Vol. 22, No. 1, Theories of Terrorism: A Symposium. (Mar., 2004), pp: 38-52.

Brant, Leonardo; Nemer, Caldeira; Lasmar, Jorge M. (2004) "O Direito

Internacional e Terrorismo Internacional: Novos Desafios à Construção da Paz”. In: Brigagão, Clóvis; Proença Jr., Domício. Paz e terrorismo: textos do Seminário Desafios para a política de segurança internacional. São Paulo: Hucitec, pp: 179-195.

Copeland, Thomas. (2001) “Is the 'New Terrorism' Really New?: An Analysis of the New Paradigm for Terrorism”. Journal of Conflict Studies, vol. XXI, n. 2, s/p. Disponível em: , <http://www.oss.net/dynamaster/file_archive/040318/47dba8 2ca2738b4c4a15a7da90c75601/OSS2003-01-12.pdf>.

Crenshaw, Martha. (1981) “The Causes of Terrorism”. Comparative Politics. Vol. 13, n. 4, pp: 379-99. . (2007) “The Debate over 'New' vs. 'Old' Terrorism”. Annual Meeting of the American Political Science Association, Chicago. Disponível em: <www.start. umd.edu/start/publications/New_vs_Old_Terrorism.pdf $>$.

Cronin, Audrey K. (2002/03) "Behind The Curve: Globalization and International Terrorism”. International Security, vol. 27, n. 3, pp: 30-58.

Diniz, Eugenio. (2002) "Compreendendo o Fenômeno do Terrorismo". Trabalho apresentado no $3^{\circ}$ Encontro Nacional da ABCP - Associação Brasileira de Ciência Política. Niterói: 22-31 de julho de 2002.

Fukuyama, Francis. (1989) “The End of History?” The National Interest, Summer, 1989.

Gofas, Andreas. (2012) “Old vs. New Terrorism: What's in a Name?”. Uluslararasi Iliskiler, vol. 8, n. 32, pp: 17-32.

Goldman, Ogen. (2010) “The Globalization of Terror Attacks”. Terrorism and Political Violence, vol. 23, n. 1, pp: 31-59.

Gurr, Nadine; Cole, Benjamin. (2000) The New Face of Terrorism: Threats from Weapons of Mass Destruction. New York: St Martins Press. 
RBED, v. 2, no 1 , jan./jun. 2015

Hoffman, Bruce. (2001) "Change and Continuity in Terrorism”. Studies in Conflict and Terrorism, Vol. 24, n. 5, pp: 417-428.

. (2006) Inside Terrorism. New York: Columbia University Press.

Huntington, Samuel P. (1996) The Clash of civilizations and the remaking of world order. New York: Simon \& Schuster.

Laqueur, Walter. (1999) The new terrorism: fanaticism and the arms of mass destruction. New York: Oxford Univesity Press.

Merari, Ariel. (1993) “Terrorism as a Strategy of Insurgency”. Terrorism and Political Violence. vol. 5, n. 4, pp: 213-251.

Montes, Marcelo; García, Roberto. (2007) "El desorden del nuevo orden mundial: terrorismo como conjunto de amenazas". La Investigación en la Universidad Nacional de Villa María, serie II, pp 191-206.

Morgan, Matthew. (2004) "The Origin of the New Terrorism”. Parameters, vol. 34, n. 1, pp: 30-31.

Moten, Abdul R. (2010) "Understanding Terrorism: Constested Concept, Conflicting Perspectives and Shattering Consequences". Intellectual Discourse, vol. 1, n. 18, pp: 35-63.

Mannik, Erik. (2009) “Terrorism: Its Past, Present and Future Prospects”. ENDC Proceedings, v. 12/2009, pp: 151-171.

Neumann, Peter. (2009) Old \& New Terrorism. Late Modernity, Globalization and the Transformation of Political Violence. Cambridge, Malden: Polity Press. Pape, Robert A. (2003) “The Strategic Logic of Suicide Terrorism”. American Political Science Review, vol. 97, n. 3, pp: 1-19.

Phillips, James. (1994) “The Changing Face of Middle Eastern Terrorism”. Heritage Backgrounder, Backgrounder \#1005 on Department of Homeland Security. October 6, 1994. Disponível em: < http://www.heritage.org/research/ reports/1994/10/bg1005nbsp-the-changing-face-of-middle-eastern-terrorism>.

Posen, Barry. (2001/02) "The Struggle against Terrorism: Grand Strategy, Strategy, and Tactics". International Security, v. 26, n. 3, pp: 39-55.

Raphaeli, Nimrod. (2003) "Financing of Terrorism: Sources, Methods, and Channels". Terrorism and Political Violence, vol. 15, n. 4, pp: 59-82.

Rapoport, David C. "Fear and Trembling: Terrorism in Three Religious 
Traditions". The American Political Science Review, vol. 78, n. 3, pp: 658-677. . (2004) “The Four Waves of Modern Terrorism”. In: Cronin: Audrey Kurth; Ludes, James M. (Eds.) Attacking Terrorism: Elements of a Grand Strategy. Washington DC: Georgetown University Press, pp: 46-73.

Saint-Pierre, Hector Luis. (2002) Formas Contemporâneas da Violência Política. Tese (Livre Docência). Franca: Faculdade de História, Direito e Serviço Social, Universidade Estadual Paulista Júlio de Mesquita Filho. 329f.

. (2010) "Grandes tendências da segurança internacional

contemporânea”. In: Jobim, Nelson; Etchegoyen, Sergio W.; Alsina, João Paulo (Orgs.) Segurança Internacional perspectivas brasileiras. Rio de Janeiro: FGV Editora, pp: 31-48.

Schmid, Alex; Jongman, Albert. (1988) Political Terrorism: A New Guide to Actors, Authors, Conceptc, Databases, Theories, and Literature. New Brunswick: Transaction Books.

Simon, Steven; Benjamin, Daniel. (2000) "America and the New Terrorism". Survival, vol. 42, n. 1, pp: 59-75.

Spencer, Alexander. (2014) "No: The New Terrorism of Al-Qaeda is Not New". In: Gotlieb, Stuart (Ed.) Debating Terrorism and Counterterrorism: Conflicting Perspectives on Causes, Contexts, and Responses. 2nd. Ed. Los Angeles: SAGE, pp: 4-15.

Conflict \& Development, N. 8, pp: 1-33. (2006) "Questioning the Concept of New Terrorism". Peace

Tilly, Charles. (1996) Coerção, Capital e Estados Europeus, 990-1992. Tradução de Geraldo Gerson de Souza. São Paulo: Editora da USP.

Wohlforht, William C. (1999) "The Stability of a Unipolar World" International Security, vol. 24, No. 1, Summer 1999, pp: 5-41.

Zarakol, Ayse. (2010) "What Makes Terrorism Modern? Terrorism, Legitimacy, and the International Relations". Review of International Studies, British International Studies Association, pp: 1-26. Disponível em: <https://www. academia.edu/408324/What_Makes_Terrorism_Modern_RIS_>. 